\title{
Rancang Bangun Data Logging Berbasis Web Server Pada Robot Balon Udara Untuk Deteksi Kebocoran Pipa Gas
}

\author{
Bagus Aji Supeno, Muhammad Rivai, dan Fajar Budiman \\ Jurusan Teknik Elektro, Fakultas Teknologi Industri, Institut Teknologi Sepuluh Nopember (ITS) \\ Jl. Arief Rahman Hakim, Surabaya 60111 \\ e-mail: bagus12@mhs.ee.its.ac.id,muhammad_rivai@ee.its.ac.id, fajarbudiman@ee.its.ac.id
}

\begin{abstract}
Abstrak-Saluran pipa gas adalah salah satu komponen terpenting dalam industri gas. Umumnya, saluran pipa gas digunakan untuk menyalurkan gas dengan jarak yang jauh terutama untuk gas alam. Deteksi kebocoran gas dan mekanisme identifikasi lokasi kebocoran gas secara realtime memiliki peranan penting dalam sistem managemen saluran pipa gas alam. Kelambatan sistem deteksi kebocoran gas dapat menyebabkan kerugian materi dan peralatan bahkan kerusakan pada lingkungan. Sistem deteksi kebocoran gas berdasarkan aliran gas hanya dapat mendeteksi kebocoran pipa gas tanpa mengetahui lokasi saluran pipa yang bocor. Sebuah balon udara dilengkapi navigasi GPS dan sensor gas dapat mendeteksi sumber kebocoran pada pipa gas dengan identifikasi lokasi berdasarkan GPS. Pada tugas akhir ini, sensor gas yang digunakan adalah sensor TGS 2611. Proses identifikasi lokasi kebocoran pipa gas menggunakan sensor GPS yang akan memberikan data lokasi dari balon udara ketika terjadi peningkatan konsentrasi gas. Data konsentrasi gas dan data lokasi dikirim ke ground station melalui gelombang radio menggunakan NRF24L01 untuk kemudian data diunggah ke database dan ditampilkan pada localhost. Jarak jangkauan maksimum balon udara dapat mendeteksi kebocoran pipa gas dengan sensor TGS 2611 adalah $15 \mathrm{~cm}$. Dibutuhkan sebuah kipas penghisap pada kotak sensor untuk membantu sensor agar lebih fokus. Identifikasi lokasi sumber kebocoran gas menggunakan sensor GPS mempunyai rata-rata error sebesar $0.03 \%$ dan $7 \%$ dengan jarak maksimum pengiriman data melalui gelombang radio sejauh 100 meter.
\end{abstract}

Kata Kunci- Kebocoran Gas, Sensor TGS2611, GPS, Balon Udara.

\section{PENDAHULUAN}

S ELAMA beberapa dekade terakhir, saluran pipa gas dengan skala yang besar dibangun untuk mengangkut gas dengan jarak yang jauh dari industri produsen ke konsumen gas. Sejak saat itu juga kebocoran dari material berbahaya yang bisa menyebabkan kerusakan lingkungan dan kehilangan materi yang diangkut dalam pipa gas sering terjadi. Kecelakaan yang disebabkan oleh adanya kebocoran pipa gas terjadi di hampir seluruh bagian di dunia, salah satunya di Kaohsiung, Taiwan, dua puluh dua orang tewas dan ratusan orang cedera akibat serangkaian ledakan yang disebabkan oleh bocornya saluran pipa gas bawah tanah [1]. Selain itu kebocoran gas juga terjadi di sebuah pemukiman di Los Angeles, Amerika Serikat. Bocornya gas methane yang disimpan di tempat penampungan bawah tanah menyebabkan polusi udara di daerah sekitar. Gas alam jenis methane tidak beracun dan tidak menimbulkan bau sesaat ketika terlepas ke udara tetapi setelah itu akan menimbulkan polusi yang sangat mengganggu [2].

Hingga saat ini, terdapat banyak sekali metode deteksi kebocoran gas yang telah dikembangkan dan dipublikasikan. Metode-metode tersebut dapat dikategorikan dalam metode berbasis hardware dan metode model matematika secara prinsip, termasuk dalam monitoring melalui gambar, pengukuran menggunakan sensor akustik, negative pressure, pengawasan satelit, stabilisasi massa atau volume dan metode analisis model dasar [3]. Negative pressure yang menghasilkan sensitivitas tinggi dan keandalan tinggi, metode ini merupakan salah satu metode yang lebih baik. Jumlah kerja yang banyak dapat dilakukan untuk mengembangkan metode yang efektif untuk deteksi dan identifikasi lokasi kebocoran secara kontinyu pada sistem saluran pipa gas menggunakan metode negative pressure [4]. Tetapi dari beberapa penelitian diatas data yang didapat belum dapat dikumpulkan secara realtime dan belum dapat memberi informasi posisi secara tepat. Hal ini dapat diatasi dengan menggunakan data logging berbasis webserver.

Maka dibutuhkan sebuah inovasi identifikasi kebocroan gas yang lebih baik dengan harapan agar proses deteksi kebocoran gas semakin akurat dan efektif dengan menggunakan robot balon zeppelin yang dikendalikan secara autonomous serta dapat mengumpulkan data konsentrasi gas yang terukur di sekitar pipa dan identifikasi lokasi kebocoran secara akurat dikirim melalui komunikasi tanpa kabel yang memanfaatkan pita gelombang radio ke webserver untuk selanjutnya dilakukan analisa dari data yang diperoleh.

\section{TEORI PENUNJANG}

\section{A. Sensor Semikonduktor}

Sensor gas adalah sensor yang berfungsi untuk mengukur senyawa gas polutan yang ada di udara seperti karbon monoksida, hidrokarbon, nitrooksida, dan lain-lain. Sensor gas semikonduktor memiliki banyak jenis yang dibedakan oleh sensitivitas sensor tersebut. Prinsip kerja dari sensor gas semikonduktor ini ialah ketika mendeteksi adanya perubahan konsentrasi gas di udara sesuai dengan target gas yang dituju maka resistansi dari sensor akan semakin rendah, dan akan berangsur-angsur naik ketika konsentrasi gas di udara sekitar sensor gas semikonduktor mulai turun secara perlahan.

1) Prinsip Kerja Sensor Gas Tipe Semikonduktor

Sensor gas tipe semikonduktor terdiri dari elemen sensor, dasar sensor dan tudung sensor. Elemen sensor menggunakan bahan-bahan seperti timah(IV)oksida $\mathrm{SnO}_{2}$, wolfram (VI) oksida $\mathrm{WO}_{3}$, dan lainlain. Bila suatu kristal oksida logam seperti $\mathrm{SnO}_{2}$ dipanaskan pada suhu tinggi tertentu di udara, oksigen teradopsi pada permukaan kristal dengan muatan negatif. Elektron - elektron donor pada permukaan kristal ditransfer ke oksigen teradopsi, sehingga 
menghasilkan suatu lapisan ruang bermuatan positif. Akibat dari peristiwa tersebut potensial permukaan terbentuk yang akan menghambat aliran elektron.Proses didalam sensor arus listrik mengalir melalui bagian - bagian penghubung (batas butir) kristalkristal mikro $\mathrm{SnO}_{2}$. Di batas-batas antar butir, oksigen yang teradopsi membentuk penghalang potensial yang menghambat muatan bebas bergerak.

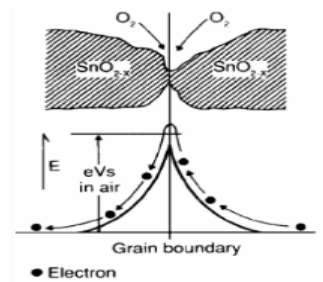

Gambar 1. Bentuk penghalang potensial antar butir Kristal mikro $\mathrm{SnO}_{2}$ saat tanpa adanya gas [5].

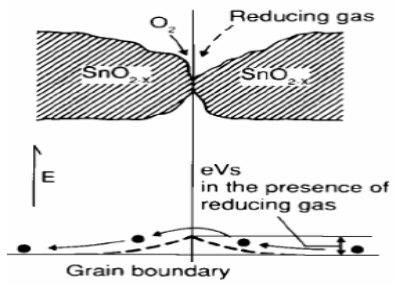

Gambar 2. Model penghalang potensial antar butir dalam lingkungan gas [5].

Ketika model penghalang potensial antar butir dalam lingkungan gas atau terdeteksi gas, kerapatan oksigen teradopsi bermuatan negatif pada permukaan semikonduktor sensor menjadi berkurang, sehingga ketinggian penghalang pada batas antar butir berkurang yang menyebabkan berkurangnya tahanan butir dalam lingkungan gas.

2) Sensor Semikonduktor TGS2611

TGS 2611 Methane dan Natural Gas sensor gas untuk mendeteksi besarnya kontaminasi metana dan gas alam dalam udara dengan spesifikasi:

1. Target gas : Methane dan Natural Gas

2. Resistance Output

3. Typical detection range : $500-10000 \mathrm{ppm}$

4. Circuit Voltage: 5VDC.

5. Heater Voltage : 5VDC/AC

6. Sensor Resistance: $10 \mathrm{~K}-90 \mathrm{~K}$ ohm di udara.

Sensor ini akan stabil pada nilai output tegangan 2.5 volt [5].

\section{B. GNSS (Global Navigation Satellite System)}

GNSS (Global Navigation Satellite System) merupakan suatu metode pengoperasian satelit yang terdiri dari gabungan beberapa sistem satelit navigasi seperti GPS (Amerika), GLONASS (Rusia), Galileo (Uni-Eropa), dan Beidou (Cina). GNSS disediakan untuk kepentingan sipil maupun militer di seluruh dunia. GNSS menyediakan informasi posisi, ketinggian, kecepatan, dan waktu dari receiver, sehingga memungkinkan pengguna untuk mengetahui lokasi tepat mereka dimanapun di permukaan bumi.

\section{1) Latitude dan Longitude Standar NMEA}

NMEA merupakan sebuah standarisasi laporan yang dikeluarkan oleh receiver GPS. Standarisasi NMEA sudah ada sejak tahun 1983. NMEA ini berisikan beberapa baris data yang diterima oleh GPS receiver, diantara data-data tersebut antara lain: GPGGA (Global Positioning system fixed data), GPGLL (geographic position latitude longitude), GDGSA (GNSS DOP active satellites), GPGSV (GNSS satellites in view), GPRMC (recommended minimum specific GNSS),

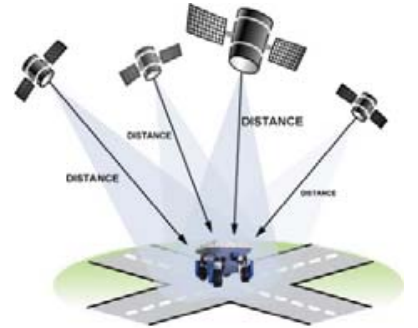

Gambar 3 Mendeteksi posisi dengan GNSS [6]

GPVTG (course over ground speed). Latitude adalah garis horizontal atau mendatar bumi dengan titik 0 adalah sudut ekuator bumi. Semakin (+) menunjukkan ke arah kutub utara dan semakin (-) akan menunjukkan ke arah kutub selatan. Longitude merupakan garis lintang bumi dengan penunjukkan angka 0 menunjukkan negara inggris atau kota Greenwich [6].

Data posisi berupa latitude dan longitude disajikan dalam kode GPGGA dimana dalam kode GPGGA juga terdapat berbagai macam data apabila masih dalam keadaan data yang utuh. Berikut contoh parsing data dari data GPGGA yang diterima oleh GPS:

\$GPGGA,123519,4807.038,N,01131.000,E,1,08,0.9,545.4,M,46. $9, \mathrm{M},{ }^{*} 47$

dimana:

GGA Global Positioning System Fix Data

123519 Data waktu fix diambil pada 12:35:19 UTC

4807.038,N Latitude 48 derajat 07.038' N

01131.000,E Longitude 11 derajat 31.000' E

$1 \quad$ Fix quality: $0=$ invalid

$1=$ GPS fix (SPS)

$2=$ DGPS fix

$3=$ PPS fix

$4=$ Real Time Kinematic

5 = Float RTK

6 = Estimasi (dead reckoning)

$7=$ Mode manual input

8 = Mode simulasi

08 Banyaknya satelit yang terekam

$0.9 \quad$ Pencairan posisi horizontal

545.4,M Altitude, Meter, dibawah permukaan laut

46.9,M Ketinggian geoid dibawah WGS84 ellipsoid

(kosong) Waktu dalam detik sejak update terakhir

(kosong) ID stasiun DGPS

*47 Jumlah data, selalu diawali dengan* [6].

\section{Data logging dan Web server}

Data logging adalah suatu proses yang digunakan oleh sebuah komputer untuk mengumpulkan data melalui sensor, menganalisa data dan menyimpan hasil keluaran sebagai hasil analisa dan pengumpulan data. Data logging termasuk dalam sistem kontrol tentang bagaimana sebuah komputer dapat mengumpulkan data dan menganalisa data. Data logging biasa digunakan pada sebuah percobaan ilmiah dan sebuah sistem monitoring dimana dibutuhkan pengumpulan informasi secara cepat dibandingkan dengan kemungkinan kemampuan manusia untuk bisa mengumpulkan informasi serta akurasi dari informasi yang dikumpulkan sangat penting.

Sebuah contoh dimana pada sebuah sistem data loging dapat mengumpulkan informasi termasuk dalam suhu, suara, frekuensi, getaran, waktu, intensitas cahaya, arus listrik dan tekanan yang dapat berubah menurut satuan waktu [7].

Web server adalah sebuah teknologi informasi yang memproses suatu pemintaan melalui HTTP (HyperText Transfer Protocol), sebuah protokol jaringan dasar yang digunakan untuk mengirimkan informasi ke world wide web. Fungsi utama dari sebuah web server 
adalah untuk menyimpan, memproses dan mengirim sebuah halaman web kapada klien. Komunikasi antara klien dan server melalui layanan HTTP. Halaman dikirim dalam bentuk dokumen HTML(HyperText Markup Language), yang dapat berisi gambar, lembar kerja dan sebuah catatan yang ditambahkan pada teks. Web server tidak selalu melayani basis world wide web, dapat juga ditemukan pada sebuah sistem terintegrasi seperti printer, router, webcam dan layanan jaringan lokal. Web server juga biasa digunakan pada sistem monitoring dan atau untuk mengatur divais sesuai permintaan. Hal ini berarti ada sebuah tambahan aplikasi yang terinstal pada komputer klien, dengan permintaan yang dikirim melalui sebuah web browser atau sistem operasi [7].

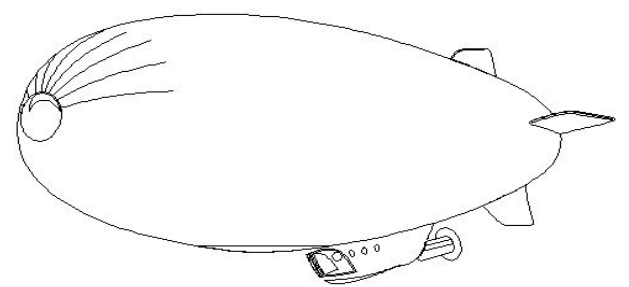

Gambar 4 Struktur balon zeppelin [8]

\section{Balon Udara}

Balon udara adalah sebuah balon yang berisi gas helium sehingga mempunyai daya angkat. Salah satu jenis balon udara adalah balon zeppelin, yang merupakan sebuah balon udara berbentuk cerutu raksasa yang dapat terbang terarah karena mempunyai mesin dan kemudi.

Balon zeppelin menggunakan helium sebagai gaya angkat untuk terbang yang ditampung pada envelope. Kontrol utama dari balon zeppelin pada dasarnya menggunakan motor yang berfungsi untuk pendorong ke depan, elevate (mendorong keatas atau kebawah) dan rudder (untuk membelokkan kemudi) [8].

\section{DISAIN SISTEM DAN IMPLEMENTASI}

Perancangan sistem meliputi perangkat keras dan perangkat lunak. Perangkat keras terbagi meliputi perangkat mekanik dan elektrik, dan perangkat lunak meliputi program python Raspberry PI dan database pada phpMySQL serta tampilan pada localhost yang menggunakan pemrogaman javascript dan Python.

\section{A. Perancangan Perangkat Keras}

Perangkat Keras terdiri dari perangkat elektrik dan perangkat mekanik. Perangkat elektrik meliputi powersupply, rangkaian sensor, raspberry PI, pembacaan nilai ADC, komunikasi serial dan komunikasi radio NRF24L01. Untuk perangkat mekanik adalah balon udara yang telah dilengkapi dengan controller dan aktuator.

\section{B. Perancangan Perangkat Lunak}

Perangkat lunak yang dirancang terdiri atas dua bagian yaitu perangkat lunak pada Raspberry pi dan perangkat lunak pada Database serta pada tampilan localhost. Perangkat lunak pada Raspberry pi sebagai transceiver berupa perangkat lunak untuk melakukan proses ADC sebagai konversi data sensor analog menjadi data digital dan proses pengiriman melalui gelombang radio. Sedangkan pada Raspberry pi sebagai receiver ialah melakukan proses penerimaan data hasil konversi analog ke digital kemudian proses konversi dalam bentuk satuan Ppm serta proses upload ke database php MySQL, untuk perangkat lunak yang dirancang pada database yaitu untuk mengumpulkan data konsentrasi gas di udara dan data GPS ynag menunjukkan lokasi dari konsentrasi gas.
Perangkat lunak pada localhost dirancang untuk menampilkan data yang telah dikumpulkan di database serta menampilkan lokasi kebocoran jika konsentrasi gas terlampau sangat besar.

Pada perancangan perangkat lunak untuk membaca nilai tegangan, tegangan maksimum dari keluaran sensor yang mampu diterima oleh controller adalah 3,3 volt dengan input tegangan sumber sebesar 3,3 volt. Dengan rumus konversi nilai tegangan ke dalam bentuk nilai digital sebagai berikut:

$\mathrm{ADC}=\frac{\operatorname{tm} x 2 m}{\text { Hrett }}$

Untuk bisa menentukan koordinat maka data yang digunakan ialah data latitude dan data longitude. untuk mendapatkan nilai longitude dan altitude maka terlebih dahulu mengambil data tersebut dari sensor GPS yang digunakan, karena data yang disajikan oleh GPS terlalu banyak maka terlebih dahulu dilakukan parsing data. Proses parsing data merupakan proses pemisahan data yang disajikan oleh sensor. Proses ini membutuhkan protokol tertentu untuk bisa membaca data yang kita inginkan. Berikut rumus untuk mendapatkan jarak objek terhadap permukaan bumi berdasarkan data latitude dan longitude:

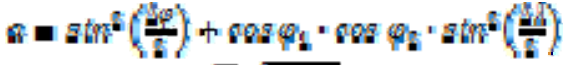

$$
\begin{aligned}
& c=2 \cdot \operatorname{ctan} 2(x \sqrt{\alpha} \cdot \sqrt{1-\kappa)} \\
& \text { d }=E \cdot v
\end{aligned}
$$

Dimana :

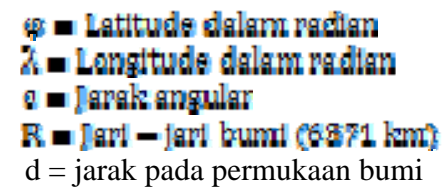

Proses Upload Data ke Database

Setelah data diterima oleh receiver, data hasil konversi ADC tersebut akan dikonversikan kedalam satuan konsentrasi gas yaitu ppm(part per million) dengan rumus sebagai berikut:

$$
\begin{aligned}
& \mathrm{Vrl}=\frac{\text { hinners }}{\mathrm{GE}}
\end{aligned}
$$

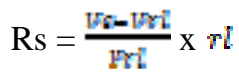

Setelah mendapat nilai Rs berdasarkan nilai ADC yang terbaca maka selanjutnya dicari persamaan untuk menghitung nilai konversi dalam satuan ppm berdasarkan tabel sensitivitas sensor TGS 2611 terhadap methane.

$$
\text { Concentration }(\mathrm{ppm})=\left(\frac{4 \mathrm{si169}}{\left(\frac{\min }{m}\right)}\right)^{225}
$$

Setelah data dikonversikan dalam satuan konsentrasi gas di udara maka selanjutnya langkah selanjutnya ialah data tersebut diupload ke database web server. Layanan database yang digunakan dalam tugas akhir ini adalah database php MySQL. Sebelum menggunakan layanan database, terlebih dahulu diinstal perangkat lunak yang mendukung sistem bekerja sinkron dengan layanan database diantaranya adalah install apache, perangkat lunak phpMyAdmin dan membuat akun di phpMyadmin, selanjutnya ialah install perangkat lunak untuk akses databse phpMySQL. Proses upload bergantung pada seberapa banyak data yang diterima tiap satu detik. Sedangkan untuk refresh database, dilakukan manual untuk keperluan tampilan 
seperti gambar 6 sedangkan logging data masih tetap berjalan meskipun belum di-refresh.

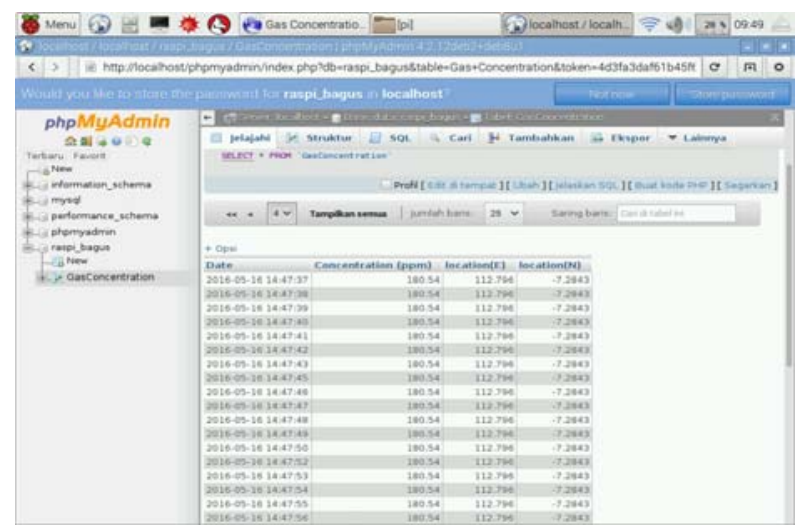

Gambar 6. Tampilan database yang telah terisi oleh data

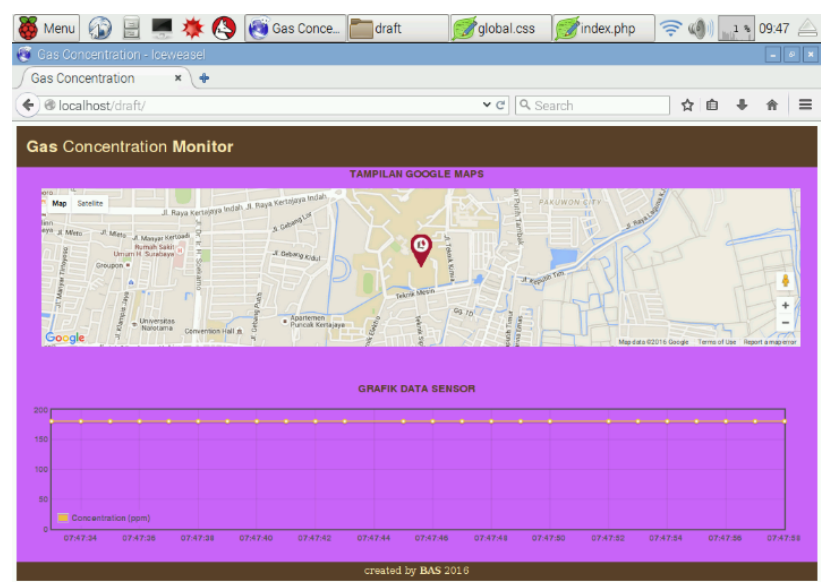

Gambar 7. Gambar tampilan localhost terintegrasi google maps

Tampilan pada localhost pada umumnya digunakan untuk representasi data konsentrasi gas di udara dalam bentuk grafik konsentrasi gas di udara terhadap satuan waktu. Data konsentrasi gas yang di udara yang ditampilkan adalah 24 data terakhir. Gambar 8 merupakan tampilan interface pada localhost yang merepresentasikan data konsentrasi gas di udara dan data koordinat yang ditampilkan pada google maps.

\section{HASIL PENGUJIAN DAN ANALISIS}

\section{A. Realisasi Desain Balon Udara}

Pada tugas akhir ini digunakan dua balon udara air swimmer yang akan diisi dengan helium. Volume dari balon udara ini adalah 0.1274 $\mathrm{m}^{3}$. Dua balon udara air swimmer mempunyai volume untuk diisi helium sebesar $0.2548 \mathrm{~m}^{3}$. balon udara air swimmer dengan volume $0.2548 \mathrm{~m}^{3}$ dapat mengangkat beban sekitar 240 gram. Dengan perhitungan sebagai berikut:

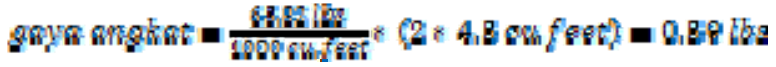

Keterangan:

1 lbs setara dengan 453,59237 gram

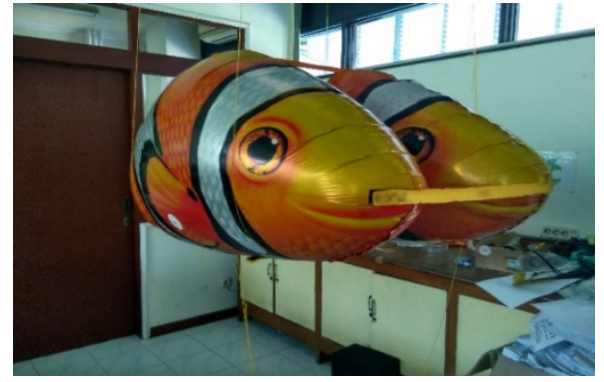

Gambar 8. Bentuk balon yang digunakan

Perangkat keras yang digunakan pada tugas akhir ini ditunjukkan oleh gambar 9 dimana perangkat keras ini yang akan ditaruh dalam badan balon.

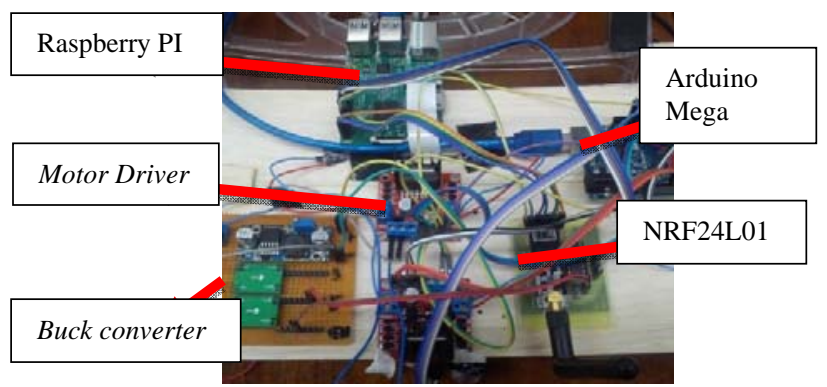

Gambar 9. Perangkat elektronik balon udara

Tabel 1. data pengujian respon sensor terhadap perubahan konsentrasi gas

\begin{tabular}{cc}
\hline \hline $\begin{array}{c}\text { Jarak } \\
(\mathrm{cm})\end{array}$ & $\begin{array}{c}\text { Tegangan Output } \\
\text { Sensor (volt) }\end{array}$ \\
\hline 0 & 3,43 \\
3 & 3,21 \\
6 & 3,12 \\
9 & 2,8 \\
12 & 2,48 \\
15 & 2,35 \\
\hline \hline
\end{tabular}

\section{B. Pengujian Sensor Gas}

Pengujian dilakukan dengan menggunakan gas yang didapat dari korek api, karena gas yang dikeluarkan dari korek api merupakan gas Iso-Butana dan sudah memiliki tekanan meskipun lemah. Dari pengujian ini akan dapat diketahui respon sensor terhadap perubahan konsentrasi gas di udara. Data hasil pengujian respon sensor berupa perubahan tegangan terhadap perubahan konsentrasi gas disajikan dalam tabel 1.

Dari pengujian ini dapat disimpulkan bahwa pendeteksian gas akan semakin baik ketika sumber gas semakin dekat dengan sensor TGS 2611. Akan tetapi, ketika sensor sudah mendeteksi adanya perubahan konsentrasi gas di udara sekitarnya maka untuk bisa kembali ke keadaan normal membutuhkan waktu yang cukup lama sehingga untuk mengatasi ini maka diperlukan sirkulasi udara yang lebih baik agar konsentrasi udara yang telah tercemar oleh gas yang akan terdeteksi akan kembali normal dengan cepat.

\section{Pengujian Data Latitude dan Longitude}

Pada pengujian ini dicari ketepatan data latitude dan longitude yang dikirim oleh modul GPS Ublox Neo-6M terhadap permukaan bumi. Data lokasi dari sensor GPS merupakan data lokasi dari jalur yang dilalui oleh balon udara. Data pengujian latitude sensor GPS ada pada gambar 10 . 
Dari data pengujian latitude pada gambar 10 diatas dapat dianalisa bahwa terdapat kesalahan pada data GPS tetapi kesalahan yang didapat masih relatif kecil karena tidak jauh berbeda dari data latitude yang diinginkan. Kesalahan yang didapat dari pengujian latitude ini memiliki rata-rata kesalahan 7\%. Maka balon udara tidak melenceng terlalu jauh dari jalur yang diinginkan.

Pada pengujian data longitude juga menggunakan metode yang sama yaitu balon udara digerakkan untuk mengikuti koordinat yang diinginkan lalu diambil data longitude selama selang waktu tertentu kemudian data yang telah terambil akan diplot dalam bentuk grafik data koordinat terhadap waktu dengan membandingkan data yang diinginkan dengan data yang diperoleh. Berikut data hasil pengujian longitude terdapat pada gambar 11 .

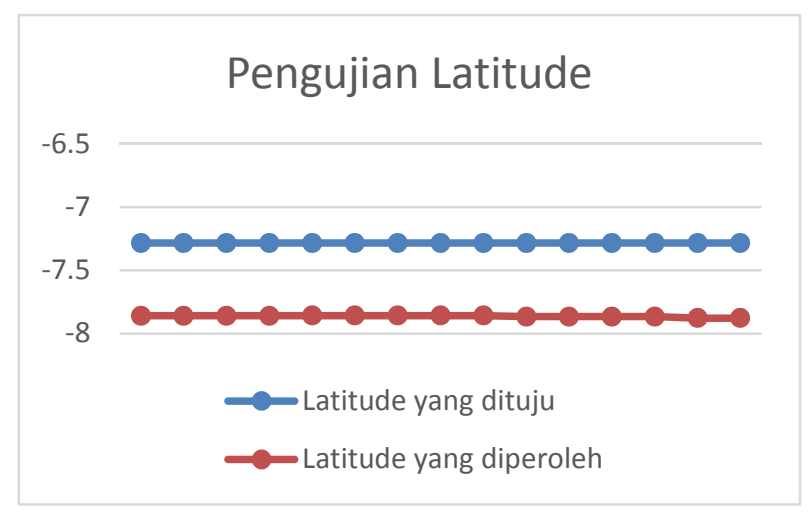

Gambar 10. Data pengujian latitude sensor GPS

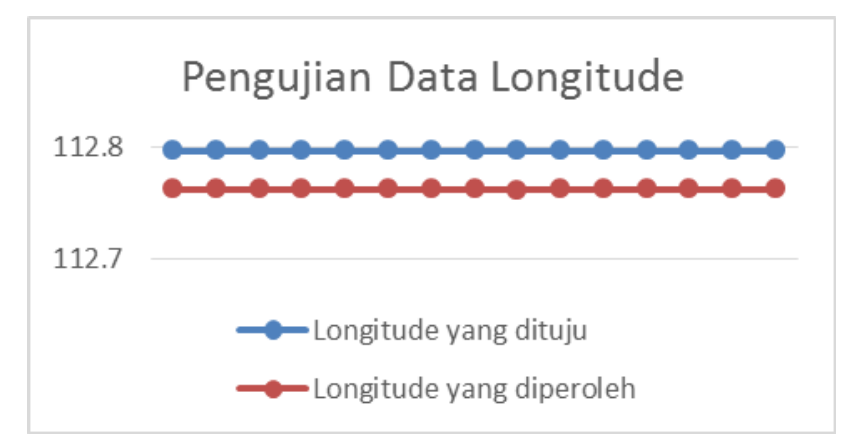

Gambar 11. Data pengujian longitude yang diperoleh

\begin{tabular}{cc} 
Tabel 2. Data hasil pengujian jarak NRF24L01 \\
\hline \hline Jarak (meter) & $\begin{array}{c}\text { Jumlah paket yang } \\
\text { diterima }\end{array}$ \\
\hline 5 & 10 \\
10 & 10 \\
15 & 10 \\
20 & 10 \\
25 & 10 \\
30 & 10 \\
35 & 10 \\
40 & 10 \\
50 & 8 \\
60 & 7 \\
70 & 7 \\
80 & 5 \\
90 & 4 \\
100 & 4 \\
\hline \hline
\end{tabular}

Dari gambar 11 diatas dapat dianalisa bahwa terdapat kesalahan pada data GPS tetapi kesalahan yang didapat masih relatif kecil karena tidak jauh berbeda dari data longitude yang diinginkan. Kesalahan yang didapat dari pengujian longitude ini memiliki ratarata kesalahan $0,03 \%$. Maka balon udara tidak melenceng terlalu jauh dari jalur yang diinginkan.

\section{Pengujian Jarak NRF24L01}

Metode pengujian jarak untuk pengiriman data melalui NRF24L01 menggunakan 10 paket data yang dengan tiap paket dikirim tiap satuan detik kemudian NRF24L01 diposisikan dalam jarak yang akan diukur lalu dilihat berapa paket data yang berhasil dikirim oleh NRF24L01. Berikut tabel hasil pengujian jarak NRF24L01.

Dari tabel 2 diatas dapat dianalisa bahwa pengiriman data melalui NRF24L01 memiliki jarak maksimum yang dapat dijangkau dengan baik yaitu 100 meter. Hal ini dapat diketahui dari banyaknya jumlah paket yang diterima oleh stasiun penerima dalam satuan 10 detik. Banyaknya paket menunjukkan keberhasilan pengiriman dan penerimaan data yang dilakukan.

\section{E. Pengujian Deteksi Kebocoran Gas}

Pengujian deteksi kebocoran gas dilakukan untuk mengetahui sistem bekerja secara keseluruhan. Mekanisme pengujian kebocoran gas dilakukan dengan cara memberikan suatu sumber gas yang mempunyai tekanan pada lintasan balon yang telah dilengkapi dengan sistem navigasi. Pengujian menggunakan sumber gas Isobutana yang didapat dari korek api. Dari pengujian ini didapat data pada database yaitu data konsentrasi gas dan data lokasi berupa latitude dan longitude seperti yang ditunjukkan oleh gambar 12 sebagai berikut:

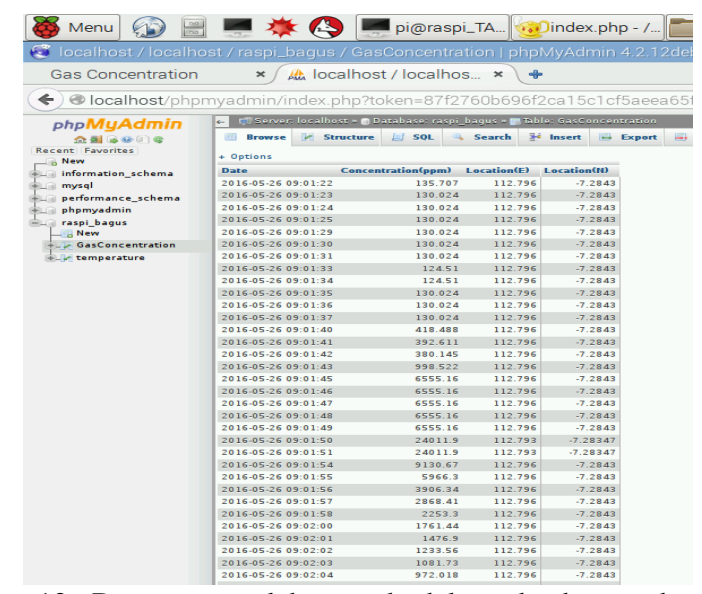

Gambar 12. Data yang telah masuk dalam database sebagai data logger

Dari data-data yang ada pada gambar 12 tersebut diplot dalam bentuk grafik. Untuk grafik yang pertama yaitu grafik konsentrasi gas dalam satuan ppm(part per million). Grafik konsentrasi gas yang telah terukur ini akan lebih membantu dalam menggambarkan besaran konsentrasi yang telah masuk ke data logger. Karena reprentasi dalam bentuk grafik maka akan tampak lebih jelas saat konsentrasi gas bertambah besar. Grafik konsentrasi gas ditampilkan pada gambar 13 sebagai berikut.

Dari gambar 13 diatas dapat dianalisa bahwa terjadi lonjakan besaran konsentrasi yang terukur pada dua titik lokasi dan dapat ditarik kesimpulan bahwa terjadi kebocoran gas pada dua titik tersebut. Data selanjutnya yang diilustrasikan yaitu data lokasi yang merupakan jalur yang dilalui oleh balon udara. Visualisasi data lokasi melalui grafik 3 dimensi yang menggambarkan jalur secara jelas. Visualisasi 3 dimensi dari jalur yang dilalui balon udara ditampilkan pada gambar 14 grafik 3 dimensi tersebut adalah hasil proyeksi dari latitude, longitude dan data waktu penerimaan data pada data logger. 
Dari dua grafik gambar 13 dan gambar 14 tersebut sudah dapat diketahui besar konsentrasi dari gas yang diukur dan jalur yang dilalui oleh balon udara,

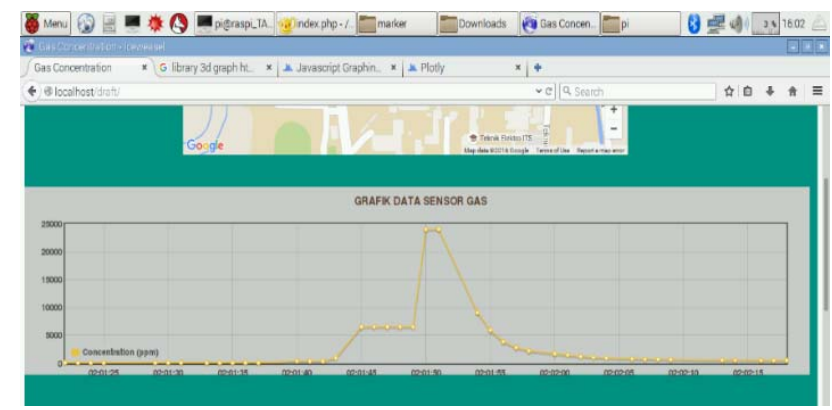

Gambar 13. Grafik konsentrasi gas yang telah terukur

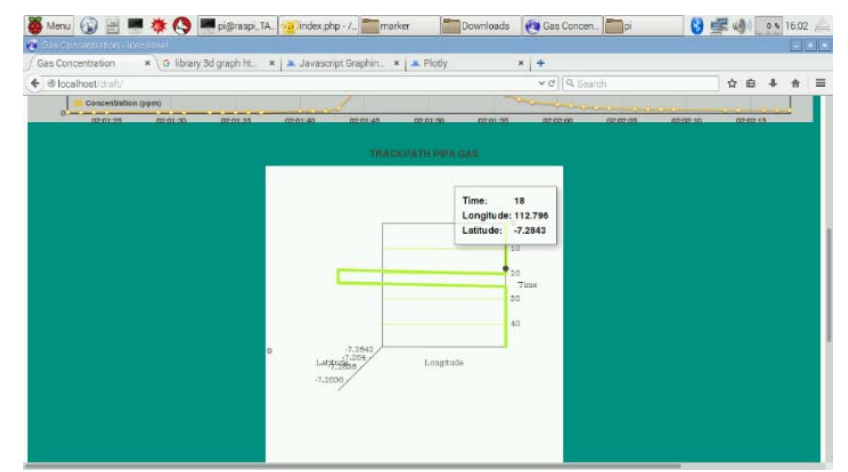

Gambar 14. Grafik jalur yang dilalui balon udara

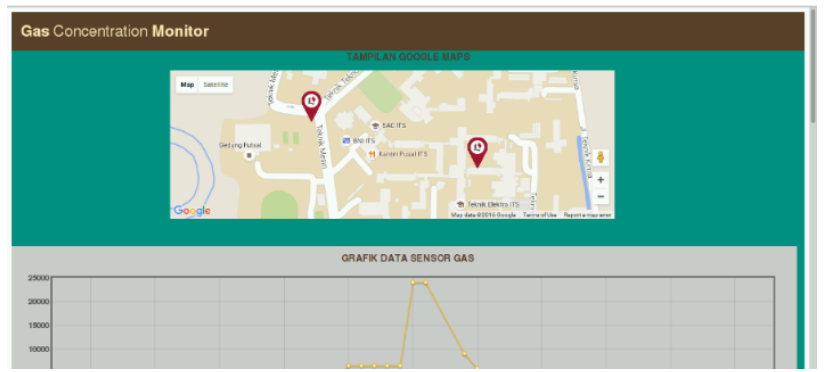

Gambar 15. Penanda lokasi saat terjadi kebocoran gas atau peningkatan konsentrasi gas

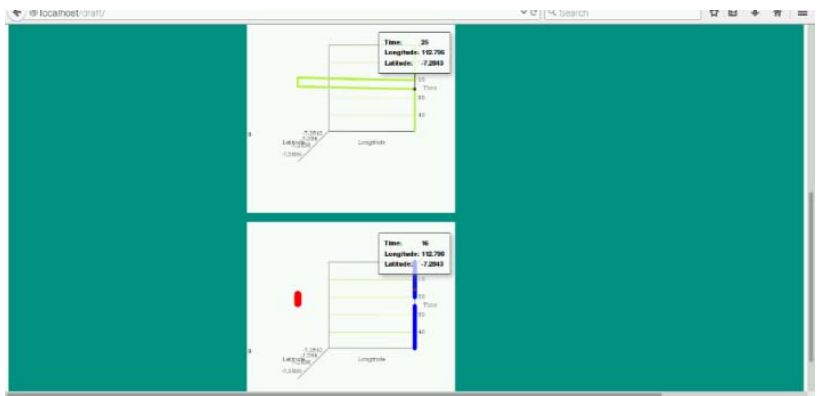

Gambar 16. Penanda terjadinya kebocoran gas melalui grafik lokasi terhadap waktu

kemudian untuk sistem penanda adanya kebocoran gas yang terjadi menggunakan dua buah penanda yaitu penanda yang pertama adalah marker pada tampilan google maps dan yang kedua adalah perbedaan warna pada grafik jalur yang dilalui robot.
Dari tampilan gambar 16 diatas didapat lokasi dimana terjadi peningkatan konsentrasi gas dengan adanya dua marker pada google maps diatas.

Dari gambar 16 diatas terdapat analisa dari penanda yang kedua yaitu terjadinya peningkatan konsentrasi gas menyebabkan perbedaan warna yang diplot pada grafik, warna merah menunjukkan jalur balon udara dengan konsentrasi gas tinggi terjadinya lonjakan konsentrasi gas sedangkan warna biru merupakan data lokasi dengan konsentrasi gas yang rendah. Dari grafik tersebut juga dapat diketahui data keberapa yang terjadi perbedaan warna karena adanya peningkatan konsentrasi gas. Sistem dapat mendeteksi adanya kebocoran gas dengan rentang konsentrasi yang diinginkan menggunakan dua penanda yaitu marker pada tampilan google maps yang menunjukkan lokasi dalam bentuk peta dan menggunakan perbedaan warna pada plot 3 dimensi dari jalur yang dilalui oleh robot balon udara.

\section{KESIMPULAN}

Telah terealisasi balon udara dengan sistem navigasi berbasis GPS dan Inertial Measurement Unit untuk deteksi kebocoran pipa gas dengan terdiri dari sensor gas TGS 2611, sensor GPS Ublox Neo-6M dengan kontroller Raspberry PI dan arduino Promini, komunikasi data menggunakan NRF24L01 dan database MySQL sebagai data logger dan localhost yang terintegrasi dengan google maps sebagai interface. Berdasarkan hasil pengujian dan analisis, dapat diperoleh kesimpulan sebagai berikut:

Sensor TGS2611 mendeteksi sumber gas berupa alkohol dengan jarak maksimal $15 \mathrm{~cm}$. Terdapat error data koordinat dari sensor GPS Ublox Neo-6M sebesar 0,576 atau 7\% untuk latitude dan 0,000301 atau $0,03 \%$ untuk longitude. Pengiriman data melalui gelombang radio menggunakan NRF24L01 dapat dilakukan dengan jarak maksimum 100 meter error didapat ketika penerimaan data mengalami delay ketika jarak semakin jauh atau terhalang oleh suatu objek. Unggah data ke database sudah dapat dilakukan secara realtime berdasarkan data yang diterima oleh stasiun penerima. Sistem mampu mengidentifikasi lokasi sumber kebocoran pipa gas dengan menggunakan marker yang ditampilkan melalui localhost yang terintegrasi dengan google maps serta melalui perbedaan warna dari plot 3 dimensi jalur yang dilalui robot balon udara.

\section{DAFTAR PUSTAKA}

[1] Dewi, Santi. 2014. Ledakan Gas di Taiwan Bos Perusahaan Kimia Minta Maaf. VivanewsBlog: Dunia.viva.news.

[2] Patnistik, Egidius. 2016. Kondisi Darurat di Pinggir Los Angeles Akibat Kebocoran Gas. KompasBlog: Kompas.

[3] Panjaitan Berkat, Siringo-Ringo Berliana, dkk. 2013.Sensor Gas. Medan: Technology Science, Sains, fisika.

[4] Figaro.2014.Datasheet2611,http://www.figarosensor.com/products/2611 .pdf (diakses 1 Februari 2016)

[5] Abi Nawang Gustica, Muhammad Rivai, Tasripan, 2014. Implementasi Sensor Gas pada Kontrol Lengan Robot untuk Mencari Sumber Gas. JURNAL TEKNIK POMITS Vol. 3, No. 1, pp.F.90-95

[6] Princeton.GNSS,http://www.princeton.edu/ alaink/Orf46F07 /GNSS.pdf (diakses 1 Februari 2016)

[7] Wikipedia. "What is Data Logging and web server". Diakses pada 4 Januari 2016. https://id.webopedia .org/what is data logging and web server/.

[8] Hain, James. 2000. "Lighter-than-air Platforms (Blimps and Aerostats) for Oceanographic and Atmospheric Research and Monitoring”, Associated Scientists at Woods Hole. 